\title{
Developing and evaluation of orodispersible tablets containing caffeine
}

\author{
Robert-Alexandru VLAD ${ }^{1}$, Elena-Beatrice TRIFAN ${ }^{1}$, Paula ANTONOAEA ${ }^{1}$, \\ Emőke-Margit RÉDAI ${ }^{1}$, Béla KOVÁCS ${ }^{2}$, Nicoleta TODORAN ${ }^{1}$, Anamaria TATARU1 ${ }^{1}$, \\ Adriana CIURBA ${ }^{1}$ \\ ${ }^{1}$ Department of Pharmaceutical Technology and Cosmetology, Faculty of Pharmacy, "George Emil Palade" \\ University of Medicine, Pharmacy, Science and Technology, Targu Mures, Romania \\ ${ }^{2}$ Department of Pharmaceutical Biochemistry and the Chemistry of Environmental Factors, Faculty of \\ Pharmacy, "George Emil Palade" University of Medicine, Pharmacy, Science and Technology, Targu Mures,
}

Romania

\begin{abstract}
Starting from the premise that a reduced number of active pharmaceutical ingredients (APIs) are used to treat hypotension, the aim of this study consisted of developing new formulations of caffeine-orodispersible tablets (CAFODTs). The formulation variables were the type of disintegrant and its concentration. The CAF-ODTs were prepared by direct compression, (CAF1, CAF2 and, CAF3) each of them containing $100 \mathrm{mg}$ of CAF / tablet. The proposed formulations were analyzed from a pharmacotechnical point of view. For the formulations developed the tablets' physical appearance, resistance to crushing, friability, disintegration behaviour, and the in vitro caffeine release were evaluated. White tablets, with a resistance to crushing decreasing in the following order CAF1 > CAF2 > CAF3 were obtained. The friability test showed that all the formulations are respecting the in-force European Pharmacopoeia (Ph. Eur. 10) requirements with values less than $1 \%$. The disintegration time for all three formulations was less than 180 seconds, the smallest time being registered in the case of CAF2 formulation, where Sodium Starch Glycolate (SSG) was used as a disintegrant (24-30 s, as a result of the different methods used. Through the in vitro releasing study, it was observed that over $99.9 \%$ caffeine was released from all three analyzed formulations. By investigating the amount of caffeine released after 1 minute, it can be noticed that the largest amount released was recorded in CAF2 formulations, where SSG was used as a disintegrant. Compared to CAF2, the amount of CAF released was reduced to half, after the first five minutes for CAF1 formulation, where sodium croscarmellose was used, and ten times lower in the case of CAF3 where no disintegrant was used. Based on the results obtained we can conclude that all three formulations are respecting the pharmacotechnical in-force officinal requirements. The presence of SSG in the CAF2 formulation led to obtaining tablets with a reduced disintegration time in comparison to the other two formulations proposed in this study.
\end{abstract}

Keywords: orodispersible tablets (ODTs), caffeine, dissolution test, pharmacotechnical properties

\section{INTRODUCTION}

Caffeine (1,3,7-trimethylpurine-2,6-dione) (CAF) represents a drug that might be used for multiple therapeutic effects. Its chemical structure is presented in Figure 1 [1]. 


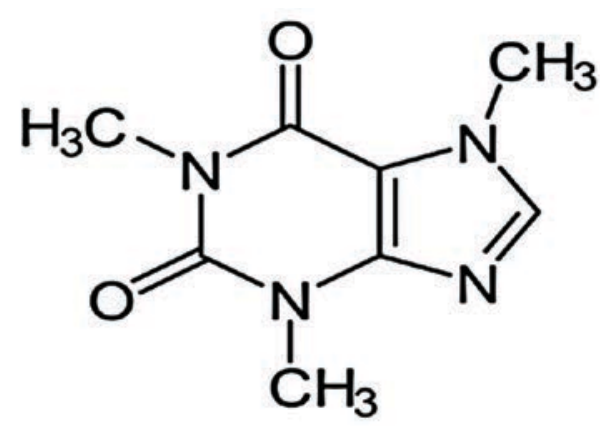

FIGURE 1. Chemical structure of caffeine the model active pharmaceutical ingredient (API) in the proposed ODTs

The therapeutic effects that can be attributed to caffeine: analgesic effect based on the vasoconstrictor effect and on its capacity of prohibiting the prostaglandins synthesis, favours the dopaminergic neuronal protection with good effects on Parkinson disease, conducts to a decrease of $\beta$-amyloid production decreasing the risk of Alzheimer disease, also, has the property of increasing the arterial tension and produces bronchodilatation $[2,3,4,5,6]$. Caffeine is a drug usually presented in medicines in combinations with other active pharmaceutical ingredients such as acetaminophen, aspirin and, codeine $[7,8]$. Caffeine is a well-known used drug to treat hypotension associated with various pathologies, but on the pharmaceutical market, no caffeinecontaining (over-the-counter) OTCs are found. Taking into account this aspect, our objective is to develop and evaluate CAF orodispersible tablets (CAF-ODTs) for patients with diseases associated with hypotension. This category of patients is not taken into consideration as a result of the fact that numerous patients are developing hypertension, so a new pharmaceutical formulation that addresses this category might represent an advantage, also, the fast occurrence of the therapeutic effect in the case of CAF-ODTs represents a huge advantage in comparison with the traditional tablets where the pharmaceutical effect occurs slower $[9,10,11]$. ODTs represent pharmaceutical formulations where the critical parameters are represented by the taste, the disintegration time and, resistance to crushing $[12,13,14]$. If these three parameters are accomplished the most important characteristics are fulfilled. The ODTs are present the following advantages in comparison with conventional tablets: the possibility of using them for patients that are experiencing dysphagia or deglutition problems, better compliance for the geriatric and paediatric patients. Also, other advantages are represented by the fact that for the administration we do not need water, as well as they are easy to handle and transported [15,16,17]. Regarding the API, an advantage is represented by the fast occurrence of the therapeutic effect owed to the bypassing first-pass effect [18]. The fast disintegration time can be a result of the presence of the superdisintegrants [19]. The superdisintegrants that presented the best properties regarding the disintegration times are sodium croscarmellose usually used in concentrations between 2-8 \%, sodium starch glycolate used in orodispersible tablets in concentrations between 4-8 $\%$ and, Crospovidone (2-5 \%) [20,21]. Sodium croscarmellose and sodium starch glycolate rely on swelling for disintegration while Crospovidone disintegration mechanism includes both swelling and wicking. Besides these superdisintegrants, new natural disintegrants are developed such as soy polysaccharides, banana starch, and mango peel pectin $[22,23,24]$.

In this study, two different superdisintegrants were used, represented by sodium croscarmellose in the first formulation and sodium starch glycolate in the second formulation, whilst in the third formulation, no disintegrant was used to highlight the importance of using a superdisintegrant when developing ODTs. $[25,26]$. This study aimed to obtain CAF-ODTs containing $100 \mathrm{mg}$ of caffeine and to evaluate the superdisintegrant effect and compression force role.

\section{MATERIALS AND METHODS}

\section{Developing orodispersible tablets with caffeine}

To obtain orodispersible tablets the following pharmaceutical ingredients were used: API - caffeine (CAF - Rochem, United States of America - USA), lactose, Lactopress ${ }^{\circledR}$ (LCT - DFE Pharma, Germany), sodium croscarmellose, Vivaso $^{\circledast}$ (CCS - JRS Pharma, Austria), sodium starch glycolate, Primojel ${ }^{\circledR}$ (SSG - DFE Pharma, Germany), Aerosil ${ }^{\circledR} 200$ (Degussa, Japan), Magnesium stearate (Alfa Aesar, USA), mannitol, (MNT - VWR Chemicals, USA) and banana flavour (BFL - JinTai, China). The proposed formulations were obtained using an eccentric press (Korsch, Germany), using $10 \mathrm{~mm}$ punches. The powders were mixed using a $\mathrm{V}$ Blender (YM-4, United Kingdom) in reverse order of their densities, the last powders added being the lubricants. Three formulations of caffeine orodispersible tablets (CAF-ODTs) were produced noted as CAF1, CAF2 and, CAF3, their composition is presented in Table 1. 
TABLE 1. The composition of the CAF-ODTs

\begin{tabular}{|c|c|c|c|c|}
\hline \multirow{3}{*}{ Ingredient's role } & \multirow{3}{*}{$\begin{array}{c}\text { Used } \\
\text { substance }\end{array}$} & \multicolumn{3}{|c|}{ Amount (mg) } \\
\hline & & \multicolumn{3}{|c|}{ Formulations } \\
\hline & & CAF1 & CAF2 & CAF3 \\
\hline Active subsstance & CAF & 100 & 100 & 100 \\
\hline Filler & LCT & 274 & 274 & 274 \\
\hline \multirow{3}{*}{ Superdisintegrant } & LCT & 274 & 274 & 274 \\
\hline & CCS & 8 & - & - \\
\hline & SSG & - & 8 & - \\
\hline \multirow[b]{2}{*}{ Lubricant } & Aerosil $^{\circledR}$ & 5 & 5 & 5 \\
\hline & $\begin{array}{c}\text { Magnesium } \\
\text { stearate }\end{array}$ & 1 & 1 & 1 \\
\hline Sweetener & MNT & 9 & 9 & 9 \\
\hline Flavour agent & BFL & 1 & 1 & 1 \\
\hline \multicolumn{2}{|c|}{ Total amount } & 398 & 398 & 390 \\
\hline
\end{tabular}

CAF - caffeine; CCS - sodium croscarmellose; SSG - sodium starch glycolate; MNT - mannitol; BFL - banana flavour

\section{The physical appearance of ODTs}

The tablets must present a uniform aspect, intact margins, and the smell, taste, and, colour should be following the properties of the excipients and API used.

\section{Uniformity of mass}

It was calculated using a four-decimal balance (KERN, Germany). For each formulation, 20 tablets were weighed and the uniformity of mass was calculated. According to the 10th European Pharmacopoeia (Ph. Eur. 10), for 18 of the tablets, the standard deviation of $\pm 5 \%$ is accepted while for two a $\pm 10 \%$ deviation from the declared mass is accepted [27].

\section{Resistance to crushing}

To obtain the values belonging to the CAF-ODTs, the force $(\mathrm{N})$ needed to break the tablet was measured using the Pharmatest 441E apparatus (Erweka, Germany). Ten CAF-ODTs for each formulation were used and their average breaking force was calculated.

\section{Friability}

To accomplish the friability, the Pharmatest PTF 10ER apparatus (Erweka, Germany) was used. For this test, 20 tablets were weighed. The tablets were tested using 25 rotations per minute (rpm) for four minutes. The operation was followed by dedusting and weighing process. The accepted value is less than $1 \%$ for the calculated friability after 100 rotations as presented in the Ph. Eur. 10 [27].

\section{Disintegration test}

Two methods were used to determine the disintegration time through two different tests. In the first case (method A), a Pharmatest PTZ Auto 1E apparatus (Erweka, Germany) was used. The disintegration time was achieved at a constant temperature of $37 \pm 0.3^{\circ} \mathrm{C}$. The disintegration time was established using disks. The second method (method B) was a much easier one using a Berzelius glass of 100 $\mathrm{ml}$, and $50 \mathrm{ml}$ of water as a disintegration media, thermostated at $37 \pm 1^{\circ} \mathrm{C}$ in which a tablet was introduced and its disintegration time was noticed. The disintegration time for orodispersible tablets has to be less than 180 seconds according to Ph. Eur. 10 [27].

\section{Dissolution test}

To evaluate the amount of API dissolved the following apparatus were used: dissolution test Erweka type I (Erweka, Germany), and a UV-VIS spectrophotometer Shimadzu 1800 (Agilent, USA), the path length of the cuvette was $1 \mathrm{~cm}$. The dissolution media used was phosphate buffer, $\mathrm{pH}=6.8$. The dissolution media volume was $900 \mathrm{ml}$, thermostated at $37 \pm 0.5^{\circ} \mathrm{C}$ using $50 \mathrm{rpm}$. $5 \mathrm{ml}$ of dissolution media were sampled at 1 , $2,5,10,15,20$ and, 30 minutes. The volume taken out of the dissolution apparatus was replaced by the same volume of $5 \mathrm{ml}$ dissolution media, kept at $37 \pm 0.5^{\circ} \mathrm{C}$. The solution was filtered using a Millipore filter with a diameter of $0.45 \mu \mathrm{m}$. To assess the caffeine concentration a spectrophotometric method was used where the specific wavelength was $273 \mathrm{~nm}$. Standard calibration curve of CAF: a stock solution of $100 \mu \mathrm{g} / \mathrm{ml} \mathrm{CAF}$ was prepared in phosphate buffer with $\mathrm{pH}=6.8$. From this solution five dilutions were made resulting the following concentrations $50 \mu \mathrm{g} / \mathrm{ml}, 40$ $\mu \mathrm{g} / \mathrm{ml}, 20 \mu \mathrm{g} / \mathrm{ml}, 10 \mu \mathrm{g} / \mathrm{ml}$, and $2 \mu \mathrm{g} / \mathrm{ml}[27,28]$.

\section{RESULTS AND DISCUSSION}

\section{Physical appearance}

White tablets with a uniform white colour, intact margins, shaped as flattened cylinders with a convex surface were obtained with a characteristic banana odour. No differences regarding the physical appearance of the three formulations were observed.

\section{Uniformity of mass}

As it can be seen in Table 2, the obtained SDs are respecting the limit value, none of the values obtained exceeding the permitted values. The largest deviation in the case of CAF1 was $+3.4123 \%$, whilst the minimum was $-3.244 \%$. For CAF 2 the SD ranges from $-3.0596 \%$ to $+2.4342 \%$ whilst for the CAF3 the SD 


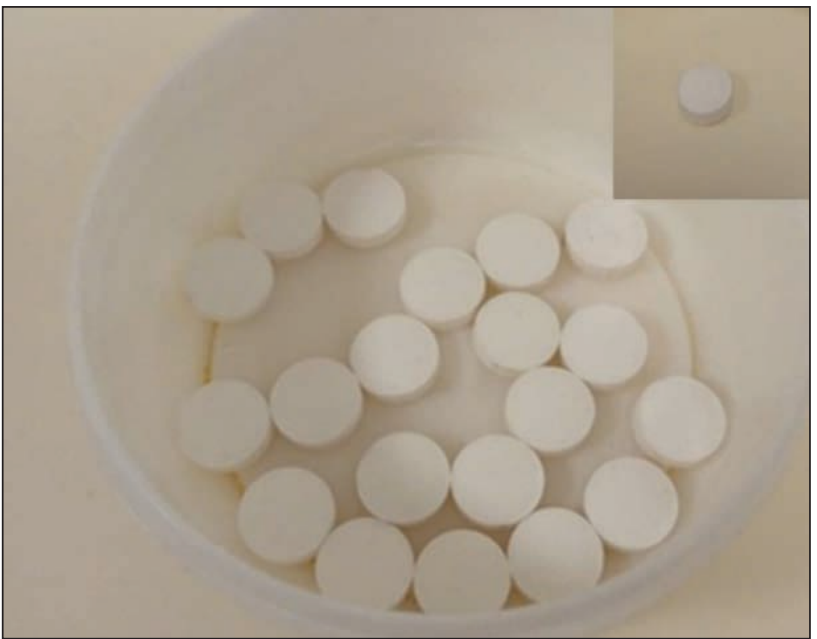

FIGURE 2. The physical appearance of the CAF-ODTs

ranged between $-4.2686 \%$ up to $+3.0972 \%$. All the tablets respected the admitted SDs of $\pm 5 \%$.

\section{Determination of the tablet's hardness}

As presented in Table 3 the resistance to crushing of the CAF-ODT is different, the first formulation presenting the highest values, a fact that represents an advantage because obtaining ODTs with good mechanical properties represents a challenge. Usually, this parameter, together with the disintegration ability represents critical factors. The CAF2 and CAF 3 presented good mechanical properties, while the first CAF-ODT presented the best mechanical properties.

\section{Friability test}

Taking into consideration the results found in Table 4, the friability and resistance to crushing results can be related because the formulation that presented the highest mechanical force needed to produce the breaking of the tablet presented also the lowest values regarding the friability test. All the developed
TABLE 2. The uniformity of mass of the CAF-ODT $(n=20)$

\begin{tabular}{|c|c|c|c|}
\hline CAF1 & CAF2 & CAF3 & $\begin{array}{c}\text { Admitted } \\
\text { deviations } \\
\text { by the Ph. } \\
\text { Eur. } 10\end{array}$ \\
\hline $\begin{array}{c}\text { Uniformity of } \\
\text { mass }(\mathrm{g}) \pm \text { SD \% }\end{array}$ & $\begin{array}{c}\text { Uniformity of } \\
\text { mass (g) } \pm \text { SD \% }\end{array}$ & $\begin{array}{c}\text { Uniformity of } \\
\text { mass }(\mathrm{g}) \pm \text { SD \% }\end{array}$ & $\begin{array}{c} \pm 5 \% \text { for } \\
18 \text { tablets } \\
\pm 10 \% \\
\text { for the } \\
\text { remained } \\
\text { two tab- } \\
\text { lets }\end{array}$ \\
\hline
\end{tabular}

CAF - caffeine; CCS - sodium croscarmellose; SSG - sodium starch glycolate; MNT - mannitol; BFL - banana flavour

TABLE 3. Resistance to crushing of the CAF-ODTs

\begin{tabular}{|l|c|}
\hline \multirow{2}{*}{ Formulation } & Resistance to crushingF2 \\
\cline { 2 - 2 } & Average values (N) \\
\hline CAF1 & $146.38 \pm 23.3$ \\
\hline CAF2 & $44.35 \pm 7.14$ \\
\hline CAF3 & $43.03 \pm 8.23$ \\
\hline
\end{tabular}

TABLE 4. Friability test results

\begin{tabular}{|l|c|}
\hline Formulation & Friability (\%) \\
\hline CAF1 & 0.32 \\
\hline CAF2 & 0.98 \\
\hline CAF3 & 0.94 \\
\hline
\end{tabular}

formulations are respecting the limit value admitted of maximum $1 \%$ friability.

\section{Evaluation of disintegration behaviour using two different methods}

In the first formulation (CAF1), a higher compression force was used while in the case of the second and third formulation (CAF2 and CAF3) the same compression force was used. If we compare the first

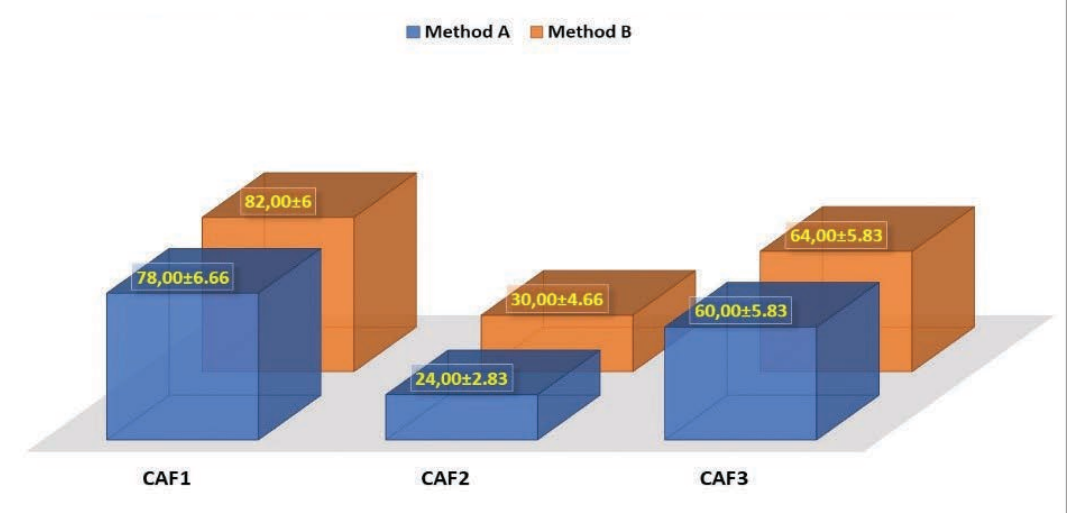

FIGURE 3. Graphical evaluation of the disintegration times (seconds) using the two proposed methods (A, B) 


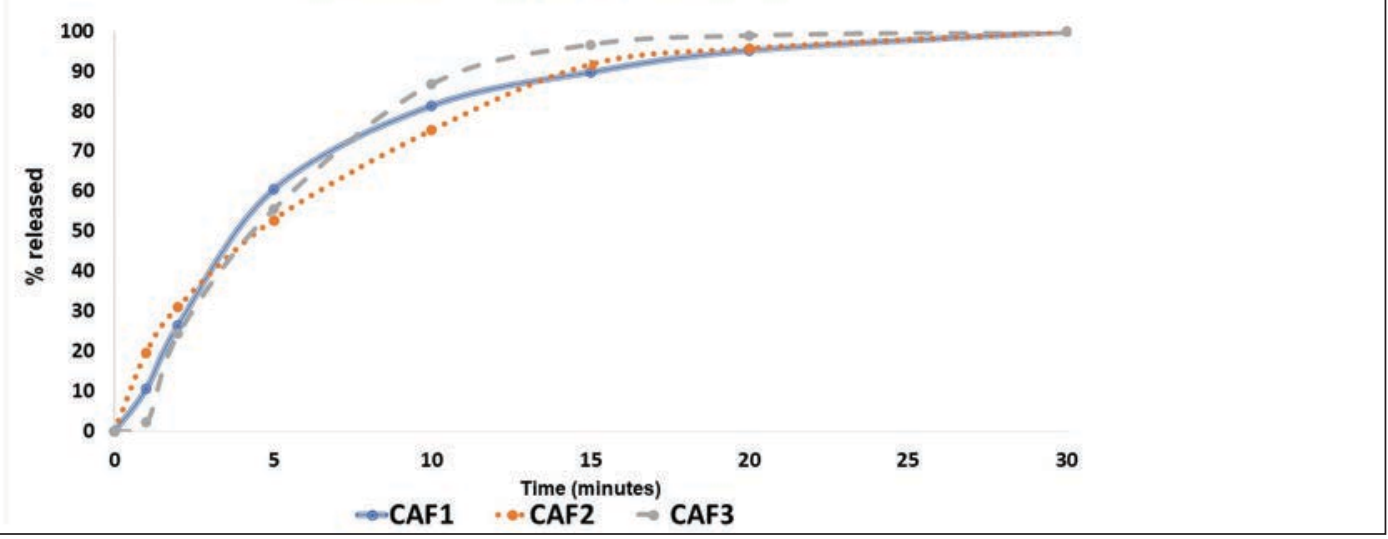

FIGURE 4. The dissolution profile of the CAF-ODTs

two formulations (CAF1 and CAF 2), where the main difference consists of the compression force used and the type of disintegrant we can conclude that the compression force has a high impact on the disintegration time. Also, in the third case (CAF3) where no disintegrant was used, smaller values of the disintegration time were obtained compared to CAF1. We can conclude that the compression force and the presence of the disintegrant influence the disintegration time, all of them being critical parameters that influence the disintegration ability. The proposed formulations respected the in-force regulations of the Ph. Eur. 10 where the disintegration time admitted has to be less than 180 seconds as shown in Figure 3.

\section{The releasing profiles of the CAF from the three CAF-ODTs}

After 30 minutes, $99.99 \%$ CAF was released from CAF1 and CAF 3 whilst from CAF2 $99.91 \%$ of CAF was released, differences in the case of the release rate occurring in the first five minutes of the determinations. As it can be seen in Figure 4 after five minutes the amounts released from all the formulations tend to be equal. An increased tableting pressure conducts to a slower release of the CAF from the CAF1. If we compare the first two formulations in the case of CAF1 only $10.63 \%$ of the API was released while in the case of the second formulation almost double was noticed to be released (19.7\%), results presented in Figure 4 and Table 5.

Taking into consideration the superdisintegrant used, its presence favours the disintegration and the fast release of the API, in the case of CAF2 almost $20 \%$
TABLE 5. Amount of CAF released from the CAF-ODTS

\begin{tabular}{|c|c|c|c|}
\hline \multirow{2}{*}{\begin{tabular}{c} 
Prelevation \\
\multirow{2}{*}{$\begin{array}{c}\text { (mime } \\
\text { (minutes) }\end{array}$}
\end{tabular}} & \multicolumn{3}{|c|}{$\begin{array}{c}\text { Amount of CAF released from the CAF- } \\
\text { ODTs (\%) }\end{array}$} \\
\cline { 2 - 4 } & CAF1 & CAF2 & CAF3 \\
\hline 0 & 0 & 0 & 0 \\
\hline 1 & 10.62 & 19.70 & 2.21 \\
\hline 2 & 26.48 & 31.12 & 24.47 \\
\hline 5 & 60.46 & 52.90 & 55.53 \\
\hline 10 & 81.45 & 75.26 & 86.80 \\
\hline 15 & 89.84 & 91.71 & 96.64 \\
\hline 20 & 95.26 & 95.72 & 98.89 \\
\hline 30 & 99.99 & 99.91 & 99.99 \\
\hline
\end{tabular}

being released after one minute while in the case of CAF3, $2.21 \%$ being released. Also, the amount of released API is influenced by the presence of the superdisintegrant as in the CAF1 and CAF2 after the first two minutes, more API was released where the superdisintegrants were used. A possible enlargement of the concentration of the disintegrant might conduct to better release rates, in this study small concentrations of $2 \%$ were used, while in other studies higher concentration of disintegrant were used, this representing an opportunity in the future studies for improving two critical parameters represented by the dissolution profile and the disintegration time [29]. Also using a natural disintegrant might represent an advantage. Usually, concentrations between 4-8 \% of CCS and SSG are being used. Many studies attest the fact that a concentration at the upper limit permitted increases the disintegration time, but if the upper limit is deprecated, the disintegration time might be affected in a negative way increasing the disintegration time, 
and decreasing the amount of the API released $[30,31,32,33]$.

For CAF1 and CAF3 formulations after 10 minutes, it can be noticed that over $80 \%$ of the total amount of the API was released whilst in the case of the CAF2, this amount was exceeded after ten minutes. After 15 minutes in two of the three formulations (CAF2 and CAF3), the amount of API released exceeded $90 \%$ while in the CAF3 formulation it was almost $90 \%$. In all of the formulations, the amount of the API released after 30 minutes was more than $99.9 \%$ fact which is in accordance with the in-force pharmacopeia.

In the study conducted by Desai and his collaborators, three types of rapid dissolving tablets were developed using ascorbic acid, ibuprofen and aspirin (three formulations for each API). In all the formulations developed the disintegration times were very small. The disintegration times in the case of aspirin and ascorbic acid were less than 15 seconds whilst in the case of ibuprofen the disintegration times could be found in the range of 20-35 seconds. Different amounts of disintegrants or a mixture of disintegrants was used. In the future studies where CAF-ODT will be developed a mixture of superdisintegrants or a higher amount of superdisintegrants might be used to improve the disintegration time. In this study the best value regarding the disintegration was recorded in the case of CAF2 where the disintegration time was between 24-30 s depending on the disintegration test used. The tablets resistance to rupture in the case of CAF2 and CAF3 is in the same range with the rapid dissolving tablets obtained by Desai and his collaborators where values between 20-45 N were noticed. In the CAF1 formulation a better resistance to rupture was noticed compared to all the formulations developed by Desai and his collaborators of $146.38 \mathrm{~N}$.

\section{CONCLUSIONS}

Three CAF-ODTs formulation were successfully obtained. For the CAF1 formulation, CCS was used, in the case of CAF2, SSG was used, while in CAF3 no disintegrant was used. The tablets were obtained by direct compression. The tablets correspond to the requirements of friability, uniformity of mass, resistance to crushing, and disintegration times. The first formulation presented good mechanical properties as a result of the increased tabletting pressure and also a good release profile, the only parameter that was affected negatively was the disintegration time which was the lowest of all the three proposed formulations. In the case of the in vitro release studies, after 30 minutes over $99.9 \%$ of the API was released, larger amounts of released API being registered in the formulations where the disintegrant was used.

\section{Conflict of interest: none declared}

Financial support: none declared

\section{REFERENCES}

1. Grama P, Pepa Oltea M, Zah CA. Effect of Caffeine on Pain Management. Acta Marisiensis - Seria Medica 2020;66(3):127131.

2. Goldstein J, Silbe Moore RA, Wiffen PJ et al. Non-prescription (OTC) oral analgesics for acute pain - an overview of Cochrane reviews. Cochrane Database Syst Rev. 2015;2015(11):CD010794.

3. Lee JB, Lee HJ, Lee SJ et al. Blood dopamine level enhanced by caffeine in men after treadmill running. Chin J Physiol. 2019;62(6):279-284.

4. Gastaldo IP, Himbert S, Ram U et al. The Effects of Resveratrol, Caffeine, $\beta$-Carotene, and Epigallocatechin Gallate (EGCG) on Amyloid- $\beta 25$--35 Aggregation in Synthetic Brain Membranes. Mol Nutr Food Res. 2020;64(22):e2000632.

5. Adamczak M, Wiecek A. Food Products That May Cause an Increase in Blood Pressure. Curr Hypertens Rep. 2020;22(1):2.

6. Mandell EW, Kratimenos P, Abman SH et al. Drugs for the Prevention and Treatment of Bronchopulmonary Dysplasia. Clin Perinatol. 2019;46(2):291-310.

7. Goldstein SD, Saper JR, Ryan RE Jr, et al. Acetaminophen, aspirin, and caffeine in combination versus ibuprofen for acute migraine: results from a multicentre, double-blind, randomized, parallelgroup, single-dose, placebo-controlled study. Headache. 2006;46(3):444-453.

8. Weiser T, Weigmann H. Effect of Caffeine on the Bioavailability and Pharmacokinetics of an Acetylsalicylic Acid-Paracetamol Combination: Results of a Phase I Study. Adv Ther. 2019;36(3):597607.

9. Hoffmann A, Daniels R. Ultra-fast disintegrating ODTs comprising viable probiotic bacteria and HPMC as a mucoadhesive. Eur J Pharm Biopharm. 2019;139:240-245.

10. Sharma S, Singh K. Oral Disintegrating Tablets - An Updated Patent Perspective. Recent Pat Drug Deliv Formul. 2020;14(3):166-190.

11. Sevilla $C$, Jiménez-Caballero PE, Alfonso V. Orally disintegrating donepezil: are the main caregivers of patients with Alzheimer's disease more satisfied with this formulation of donepezil than with the traditional one?. Rev Neurol. 2009;49(9):451-457.

12. rniak W, Jachowicz R, Pelka P. The practical approach to the evaluation of methods used to determine the disintegration time of orally disintegrating tablets (ODTs). Saudi Pharm J. 2015;23(4):437-443. 
13. Krupa A, Jachowicz R, Pędzich Z et al. The influence of the API properties on the ODTs manufacturing from co-processed excipient systems. AAPS PharmSciTech. 2012;13(4):1120-1129.

14. Georgieva YZ, Pilicheva BA, Kokova VY, et al. Taste Masking of Enalapril Maleate by the Precipitation Method. Folia Med (Plovdiv). 2019;61(3):426-434.

15. Chinwala M. Recent Formulation Advances and Therapeutic Usefulness of Orally Disintegrating Tablets (ODTs). Pharmacy (Basel). 2020;8(4):186.

16. Takano H, Uchida S, Kashiwagura Y, et al. Preparation of Cocoa Powder-Containing Orally Disintegrating Tablets of Rebamipide (Rebamipide Chocolet) and Evaluation of Their Clinical Palatability. Chem Pharm Bull. 2019;67(2):112-119.

17. Gulsun T, Akdag Y, Izat $N$ et al. Development and characterization of metformin hydrochloride- and glyburide-containing orally disintegrating tablets. Pharm Dev Technol. 2020;25(8):999-1009.

18. Aljimaee YH, El-Helw AR, Ahmed OA et al. Development and optimization of carvedilol orodispersible tablets: enhancement of pharmacokinetic parameters in rabbits. Drug Des Devel Ther. 2015;9:1379-1392.

19. Aguilar-Díaz JE, García-Montoya E, Pérez-Lozano $P$ et al. The use of the SeDeM Diagram expert system to determine the suitability of diluents-disintegrants for direct compression and their use in formulation of ODT. Eur J Pharm Biopharm. 2009;73(3):414-423.

20. Yousaf AM, Naheed F, Shahzad Y et al. Influence of sodium starch glycolate, croscarmellose sodium and crospovidone on disintegration and dissolution of stevia-loaded tablets. Polim Med. 2019;49(1):19-26.

21. Bout MR, Vromans H. Study on the Mechanism Responsible for the Incompatibility of Enalapril Maleate with Sodium Starch Glycolate [published online ahead of print, 2020 Dec 8]. J Pharm Sci. 2020;S0022-3549(20)30773-5.

22. Ursekar BM, Soni PS, Date AA et al. Characterization of soy polysaccharide and it's in vitro and in vivo evaluation for application in colon drug delivery. AAPS PharmSciTech. 2012;13(3):934-943.
23. Kaur L, Dhull SB, Kumar P et al. Banana starch: Properties, description, and modified variations - A review. Int J Biol Macromol. 2020;165(Pt B):2096-2102.

24. Alam MT, Parvez N, Sharma PK. FDA-Approved Natural Polymers for Fast Dissolving Tablets. J Pharm (Cairo). 2014;2014:952970.

25. Hobbs D, Karagianis J, Treuer T et al. An in vitro analysis of disintegration times of different formulations of olanzapine orodispersible tablet: a preliminary report. Drugs $R D$. 2013;13(4):281-288.

26. Ciurba A, Redai E, Pop I, Antonoaea P, Todoran N - Kinetics and Mechanism of Drug Release from Loratadine Orodispersible Tablets Developed without Lactose, Acta Medica Marisiensis 2017;63(1):23-26.

27. European Pharmacopoeia. 10th Edition Strasbourg: Council of Europe, 2021. Print.

28. United States Pharmacopeia and National Formulary (USP 41-NF 36). United States Pharmacopeial Convention; 2016.

29. Bisharat L, AlKhatib HS, Muhaissen S, et al. The influence of ethanol on superdisintegrants and on tablets disintegration. Eur J Pharm Sci. 2019;129:140-147.

30. Tomita T, Yamaguchi A, Nishimura N, et al. Effect of food thickener and jelly wafer on the pharmacokinetics of levofloxacin orally disintegrating tablets. Heliyon. 2019;5(11):e02764.

31. Desai PM, Er PX et al. Functionality of disintegrants and their mixtures in enabling fast disintegration of tablets by a quality by design approach. AAPS PharmSciTech 2014;15(5):1093-1104.

32. Soulairol I, Chaheen M, Tarlier $\mathrm{N}$ et al. Evaluation of disintegrants functionality for orodispersible mini tablets. Drug Dev Ind Pharm. 2017;43(11):1770-1779.

33. Hosny KM, Mosli HA, Hassan AH. Soy polysaccharide as a novel superdisintegrant in sildenafil citrate sublingual tablets: preparation, characterization, and in vivo evaluation. Drug Des Devel Ther. 2015;9:465-472. 